\title{
MODELLING ROCK MASS IMPROVEMENT USING ROCK BOLTS
}

\author{
JAN PRUŠKA
}

\author{
Czech Technical University in Prague, Faculty of Civil Engineering, Thákurova 7/2077, Prague 6, Czech \\ Republic \\ correspondence: pruska@fsv.cvut.cz
}

\begin{abstract}
Anchor support currently represents a significant reinforcing technique in underground constructions. The principles of rock bolt reinforcement action are derived from various concepts of the underground excavation stability. In recent times, rock bolt design techniques have been complemented by numerical calculations procedures. The paper describes FEM modelling of a rock bolt system for mechanical and grouted bolts.
\end{abstract}

KEYwORDs: Rock bolts, modelling, FEM.

\section{INTRODUCTION}

In recent times, rock bolting represents a significant reinforcing method, especially in tunnelling. The main effect of rock bolting is in reducing and eliminating the impact of different types of failures that occur in the rock mass (schistosity, joints, cracks, etc.) so that the reinforced rock mass can restore the equilibrium disturbed by excavating an underground work. The effect of rock bolting on the rock mass is derived using a variety of methods to determine the stability of underground excavations and the rock bolt type considered (e.g. mechanical or resin). The design and verification of the structural behaviour of rock bolts can be made by any of the following methods:

- empirical methods or using rock mass classification,

- analytical solution (e.g. rock - reinforcement contact problem),

- simple calculations based on the Fenner-Pacher curve theory,

- mathematical modelling (numerical solution of a contact problem),

- models based on discontinuity mechanics theory,

- probabilistic (stochastic) approach to determine the required loading of reinforcement anchorage.

Of the above methods, mathematical (numerical) modelling using the finite element method (FEM) is commonly used in todayâĂŹs practice. Generally, the design of bolts is a complex task that requires the knowledge of rock bolt materials, the anchor technology and the rock mass behaviour.

\section{Rock BOLTS MODELLING USING FEM}

The modelling of anchors and rock bolts by FEM is more complicated compared with the modelling of the rock mass itself. This is mainly caused by the fact that rock bolts are divided by the type of anchor (simply into two main groups: point-anchored and anchored along its entire length or predominantly over the entire length). Thus, the FEM model must necessarily take into consideration the type of rock bolt, the anchoring method and the distribution of anchoring forces in the surrounding rock. It can be used for the following task:

- modelling a rock bolt as a single element,

- homogenization of the rock bolt's area.

In current tunnelling practice, rock bolts attached to the rock along their entire length predominate, thus, the methods using the homogenization of the rock bolt's area are mostly used.

\subsection{Modelling OF ROCK BOLTS USING HOMOGENIZATION}

The principle of this procedure is based on the fact that anchors create a supporting ring in the rock mass near the excavation with characteristics of a thickwalled cylinder. The area of the supporting ring is modelled so that the elements of the finite element mesh in the supporting ring change their geomechanical properties by selecting equivalent isotropic material with improved cohesion. However, this procedure is not suitable for a clearly discontinuous rock mass (connection of rock blocks using rock bolts) because it does not consider the mechanical strength of the rock bolt's area. Czech practice uses the following procedure to increase cohesion in the rock bolt's area.

The increase of cohesion due to bolting is calculated according to the equation:

$$
C_{s}=\frac{N_{u}+\sin \varphi^{\prime}}{A_{k} \cdot 2 \cdot \cos \varphi^{\prime} \cdot \gamma_{k c}}
$$

where:

$N_{u} \quad$ loading capacity of the bolt $[k N]$,

$A_{k} \quad$ area per rock bolt $\left[\mathrm{m}^{2}\right]$,

$\varphi^{\prime} \quad$ effective angle of internal friction $\left[^{\circ}\right]$,

$\gamma_{k c} \quad$ coefficient of bolting reliability [-]. 
Cohesion of equivalent isotropic material:

$$
C_{h+s}=C_{h}+C_{s}
$$

where:

$c_{h+s} \quad$ total cohesion of rock increased due to rock bolting,

$c_{h} \quad$ original cohesion of rock,

$c_{s} \quad$ cohesion increased due to rock bolting.

If we need to take into the account the impact of the bolt on the discontinuity surface, a so-called virtual element can be used in FEM. This virtual element models discontinuity surfaces using a conventional rectangular element with a height equal to the length of the plastic area in the bolt (Fig. 1).

It is assumed for the shear modulus calculation that a failure will occur in the bolt and at the discontinuity interface at the same displacement. The shear modulus was expressed e.g. by H. Larsson [1]:

$$
G_{V P}=\frac{\tau_{b}}{u_{f}} \cdot e \cdot \frac{A_{b}}{A_{T}}+\frac{\tau_{j}}{u_{f}} \cdot e \cdot \frac{A_{j}}{A_{T}}
$$

where:

$\begin{array}{ll}G_{V P} & \text { shear modulus of the virtual element, } \\ \tau_{b} & \text { shear stress at the rock bolt failure, } \\ u_{f} & \text { block displacement at the discontinuity } \\ & \text { interface, } \\ e & \text { height of the virtual element } \\ & \text { (length of the plastic area in the bolt), } \\ A_{b} & \text { rock bolt area, } \\ A_{j} & \text { discontinuity interface, } \\ \tau_{j} & \text { shear stress at the discontinuity interface } \\ A_{T} & \text { at failure, }\end{array}$
$(\mathrm{Ab}+\mathrm{Aj})$.

\subsection{Modelling OF ROCK BOLTS AS DISCRETE ELEMENTS}

The problem of the formulation of a finite element that would describe the stabilizing effect of the rock bolt or rock anchors on the rock mass has been solved in various approaches since early FEM numerical analyses (the first models were derived around 1968). Thus, a number of special elements for describing rock bolts were developed (for bolts fixed at both ends or along their own length). These special elements are connected with specific special software or they require direct implementation in a programme code by the user. In the following part, one of the most used elements (attached to the rock along their own length) will be described. The principle of this element was presented in the thesis by Ömer Aydan in 1988 [2. It is essentially a beam element (special bolt element), which has four nodes, two of which are connected to the anchor rod and the other two to the surrounding rock - Fig. 2. The following several simplifications have been considered for deriving the stiffness matrix of this element:
- The body formed by the grouting material is considered as an axisymmetric thick-walled hollow cylinder, which, due to its shear deformation, transmits tension from the anchor rod into the surrounding rock.

- Both bolt materials (grouting material and the anchor rod) are considered with a linear elastic behaviour, and thus the relation between the stress and strain in the anchor rod and in the grouting material are described using Hooke's law.

- In terms of the coordinates of nodes, the radius of the bolt is negligible in terms of the coordinates of nodes. This presumption naturally does not apply when creating the stiffness matrix.

- The bolt considers only the existence of three types of deformation:

$\triangleright \varepsilon_{0}$ relative longitudinal deformation of the anchor rod caused by axial displacements of the nodes of the anchor rod,

$\triangleright \gamma_{g}$ shear deformation of grouting caused by different axial displacements of the nodes of anchor rods and the nodes connected with the surrounding rock,

$\triangleright \gamma_{x}$ transverse shear deformation of grouting caused by different radial displacements of the nodes connected with the surrounding rock.

The relationship of the rod bolt strain in terms of nodal displacements (the $b$ index determines the variables associated with the bolt (rod) and the $g$ index determines the values belonging to cement grout):

$$
\varepsilon^{b}=B_{b} U_{b}
$$

and the relationship of the grouting ring strain using nodal displacements

$$
\varepsilon^{g}=B_{g} \Delta U_{g}
$$

where $\mathrm{U}$ is the matrix of displacement and $\mathrm{B}$ the matrix of differential operators.

Physical equations for the linear elastic behaviour of rods and the grouting ring can be described using the above expressions as:

$$
\sigma^{b}=D^{b} \varepsilon^{b} \quad \sigma^{g}=D^{g} \varepsilon^{g}
$$

where $D$ is the relevant material stiffness matrix.

By discretization using finite elements - the equations of virtual work (it is assumed that the stress field $\sigma$ is structurally possible and the field of displacements is kinematically allowed), we get expressions for the stiffness matrix:

$K_{e}=\int B^{T} D B d(v o l)=\int_{0}^{L_{e}} \int_{0}^{r_{h}} \int_{0}^{2 \Pi} B^{T} D B d \varphi d r d z$

After the integration, we obtain the stiffness matrix of the element in the form given in fig. 3 , where 


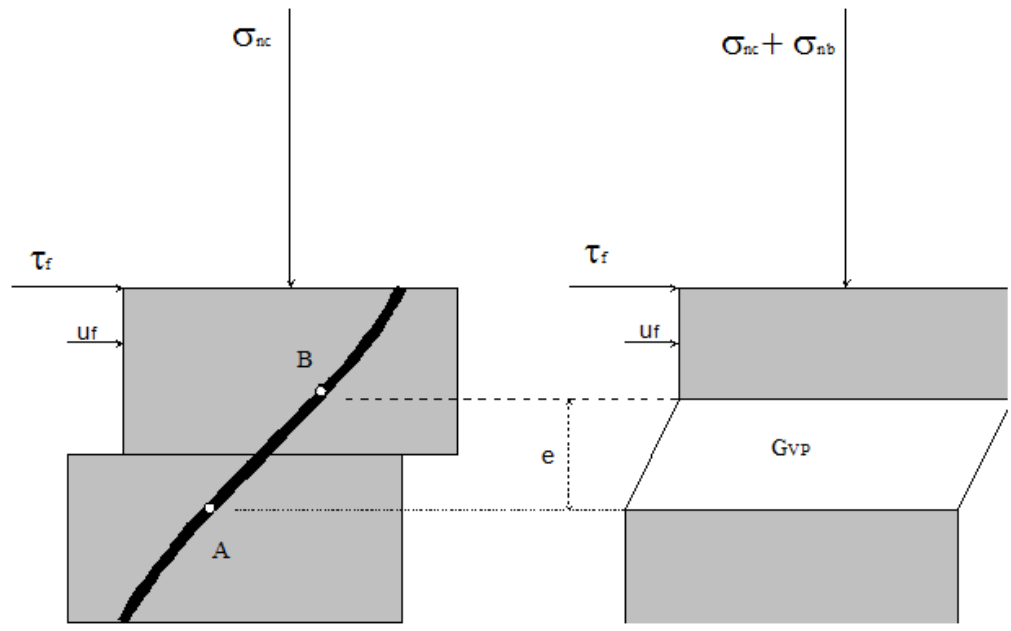

Figure 1. Virtual element for the rock with bolts.

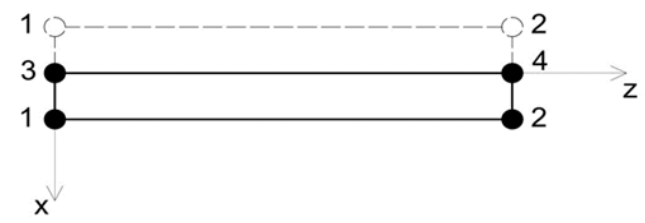

Figure 2. Scheme of a special bolt element: 1, 2 - nodes connected with surrounding rock; 3, 4 - nodes connected with the bolt rod.

$$
\begin{gathered}
K_{b}=\frac{E_{b} \cdot \Pi \cdot r_{b}^{2}}{L_{e}} \\
K_{s}=\frac{G_{b} \cdot \Pi \cdot r_{b}^{2}}{L_{e}} \\
K_{g}=\Pi \cdot G_{g} \cdot \frac{L_{e}}{3 \ln \left(\frac{r_{h}}{r_{b}}\right)}
\end{gathered}
$$

Aydan's element has been successfully implemented in scientific and commercial programmes. Fig. 4 shows an example of the application of this element to the PMD system by D. Runt [3].

\subsection{Modelling USing GeOtextile ELEMENTS}

Some authors in their publications describe the ability to model grouting bolts using geotextile elements e.g. M. Šejnoha [4. These are reinforcing elements which are continuously fixed in the earth massif. This element is, therefore, a system of two node rod elements connected in the places where the line of the geotextile intersects the edge of individual network elements - see Fig. 5. These elements can only be loaded by tensile forces, they do not have compressive strength and cannot transmit bending moments. They exhibit linear elastic behaviour (that is dependent on a specified compressive strength) and have limited tensile strength until the moment of failure.

\subsection{MODELLING USING INTERNAL FORCES IN THE ROCK MASS}

Modelling using rod elements is another possibility for describing bolts that transmit only axial forces. These elements have the ability to transfer compressive load, unlike the elements for geotextile modelling. It is also possible for this element to specify the input forces in the anchor (prestress) and not consider the prestress due to compressive load. According to some authors (e.g. [5]), the bolt root can be modelled as elements without compressive strength with contact elements. The cohesion of contact elements should be determined so that the total frictional force acting on a $1 \mathrm{~m}$ strip corresponds to the frictional force acting on the bolt (reducing cohesion by the ratio of the bolt area to the finite element area). For modelling bolts fixed along their own length, this model is unacceptable in underground engineering [6].

\subsection{MODELling USING INTERNAL FORCES IN THE ROCK MASS}

The use of internal forces is one of the oldest methods of modelling anchors and rock bolts in FEM. The principle of modelling consists in the insertion of internal forces into the rock mass at both sides of the rock bolt (head and root). This kind of plane modelling is only used for tensioned bolts or anchors. The inserted forces simulate the bracing area in the rock mass stabilized by rock bolts. However, this kind of modelling often leads to the plastification in the internal force location and to a situation where the calculation does not converge.

\section{EFFECT of installation time}

It is s quite difficult to make a sufficiently accurate model of the effect of rock bolts. We can usually only estimate the maximum possible effect. This is not only due to the established simplifications in different procedures, but the installation time of rock bolts also plays an important role (time delay due to the 


$$
\boldsymbol{K}_{e}=\left[\begin{array}{cccccccc}
2 K_{g} & 0 & K_{g} & 0 & -2 K_{g} & 0 & -K_{g} & 0 \\
0 & K_{s} & 0 & -K_{s} & 0 & 0 & 0 & 0 \\
K_{g} & 0 & 2 K_{g} & 0 & -K_{g} & 0 & -2 K_{g} & 0 \\
0 & -K_{s} & 0 & K_{s} & 0 & 0 & 0 & 0 \\
-2 K_{g} & 0 & -K_{g} & 0 & K_{b}+2 K_{g} & 0 & K_{g}-K_{b} & 0 \\
0 & 0 & 0 & 0 & 0 & 0 & 0 & 0 \\
-K_{g} & 0 & -2 K_{g} & 0 & K_{g}-K_{b} & 0 & K_{b}+2 K_{g} & 0 \\
0 & 0 & 0 & 0 & 0 & 0 & 0 & 0
\end{array}\right]
$$

Figure 3 . The stiffness matrix of the element
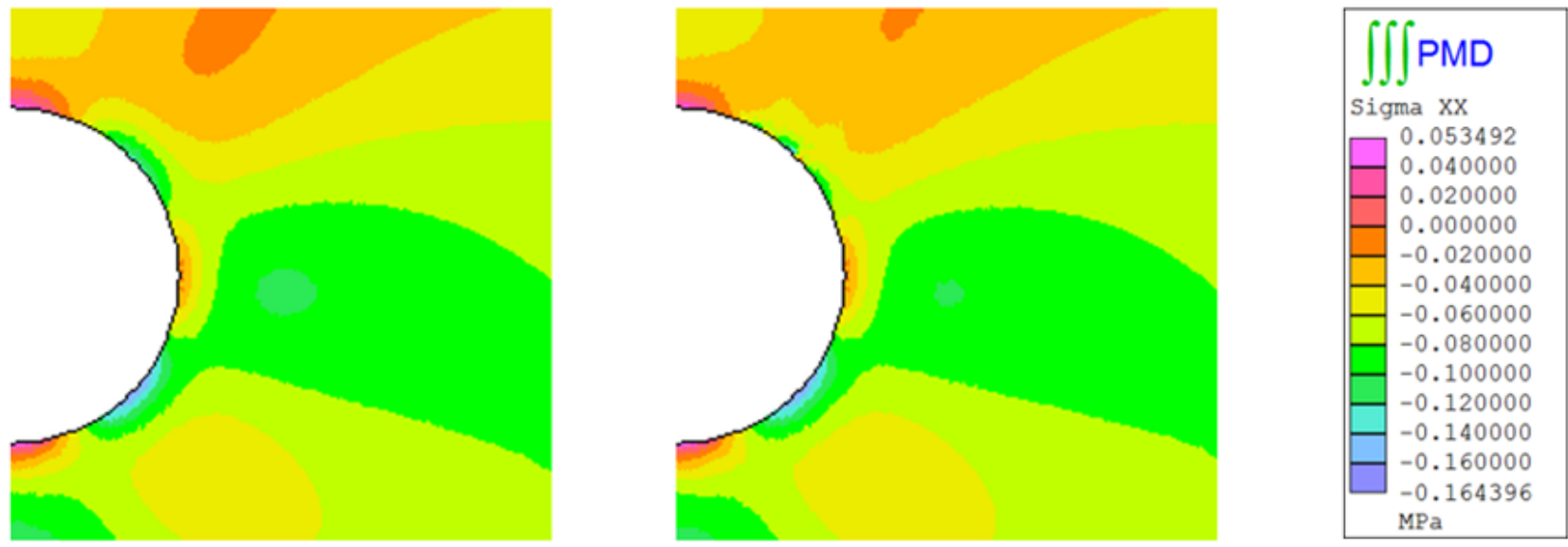

FiguRE 4. Rock behaviour in the stress - $\sigma_{x x}$ curve without rock bolts (left) and with rock bolts (right)

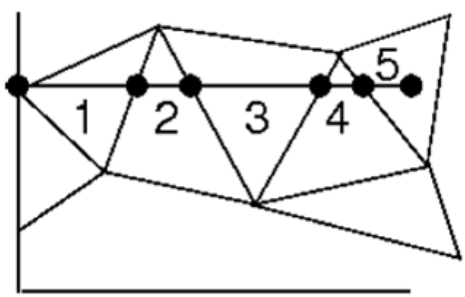

FiguRE 5. Dividing geotextiles on rod elements

application of shotcrete lining). This effect is very difficult to describe correctly in a numerical model. Rock bolts are often part of primary lining and also help to improve the final deformation. Therefore, we can only determine correctly the effects of the immediate installation of bolts or bolts installed to partially deformed lining.

\section{Conclusion}

This paper gives an overview of different approaches to rock bolts modelling using FEM for tasks related to underground structures. From the above mentioned methods, a survey clearly shows that the main approximation of rock bolts in FEM uses modified strength and deformation parameters in the rock bolt's area or specially derived elements (quantifying the effect of bolting for the rock mass). Also, FEM is not suitable for modelling a discontinuous rock mass and, therefore, a direct impact of rock bolts on discontinuities; we can say that both of the above mentioned approaches (based on the theory of continuum mechanics) are quite suitable for describing the behaviour of rock bolts. Subsequently, engineers can choose such bolt properties to reach a steady state of an underground structure and also optimize its design (based on the comparison of FEM modelling of different options).

\section{ACKNOWLEDGEMENT}

This article was written as part of a study within the project supported by the Competence Centres Program of the Technology Agency of the Czech Republic (TA CR), No. TE01020168.

\section{REFERENCES}

[1] H. Larsson, T. Olofsson. Bolt action in jointed rock. In Rock bolting : theory and application in mining and underground construction : proceedings of the International symposium on rock bolting, Abisko, 28 August - 2 September 1983, pp. 33-46. Balkema Publishers, A.A. / Taylor \& Francis The Netherlands, 1984. Godkänd; 1984; 20080926 (ysko).

[2] Ö. Aydan. The stabilisation of rock engineering structures by rockbolts. Nagoya: Nagoya university, 1989. 
[3] D. Runt, J. Pruška, J. Novotný. Modelling of rock bolts using the finite element method. In ISRM Regional Symposium - EUROCK 2015. International Society for Rock Mechanics, 2015.

[4] M. Šejnoha. Finite element analysis in geotechnical design. Saxe-Coburg Publications, Kippen, Stirling, Scotland, 2015.
[5] Z. Bittnar, J. Šejnoha. Numerické metody mechaniky 1. České vysoké učení technické v Praze, 1992.

[6] M. Hilar. Numerická analýza tektonicky porušeného horninového masivu s primární výstroji při aplikaci NRTM. Ph.D. thesis, České vysoké učení technické v Praze, 2000. 